\title{
Changes in labial capillary density on ascent to and descent
}

\section{from high altitude [version 1; peer review: 2 approved]}

\author{
Edward Gilbert-Kawai ${ }^{1}$, Jonny Coppel ${ }^{1}$, Phillip Hennis ${ }^{1}$, Michael P. Grocott ${ }^{1-3}$, \\ Can Ince ${ }^{4}$, Daniel Martin $1,5,6$
}

${ }^{1}$ University College London Centre for Altitude Space and Extreme Environment Medicine, UCLH NIHR Biomedical Research Centre, Institute of Sport and Exercise Health, London, UK

${ }^{2}$ Integrative Physiology and Critical IlIness Group, Clinical and Experimental Sciences, Mailpoint 810, Sir Henry Wellcome Laboratories, Faculty of Medicine, University of Southampton, University Hospital Southampton NHS Foundation Trust, Southhampton, UK

${ }^{3}$ Anaesthesia and Critical Care Research Unit, University Hospital Southampton NHS Foundation Trust, Southhampton, UK

${ }^{4}$ Department of Intensive Care, Erasmus MC University Hospital Rotterdam, Rotterdam, The Netherlands 5 University College London, Division of Surgery and Interventional Science, Royal Free Hospital, London, UK

${ }^{6}$ Erasmus MC-Sophia Children's Hospital, Rotterdam, The Netherlands

V1 First published: 30 Aug 2016, 5:2107

https://doi.org/10.12688/f1000research.7649.1

Latest published: 30 Aug 2016, 5:2107

https://doi.org/10.12688/f1000research.7649.1

\section{Abstract}

Present knowledge of how the microcirculation is altered by prolonged exposure to hypoxia at high altitude is incomplete and modification of existing analytical techniques may improve our knowledge considerably. We set out to use a novel simplified method of measuring in vivo capillary density during an expedition to high altitude using a CytoCam incident dark field imaging videomicroscope.

The simplified method of data capture involved recording one-second images of the mucosal surface of the inner lip to reveal data about microvasculature density in ten individuals. This was done on ascent to, and descent from, high altitude. Analysis was conducted offline by two independent investigators blinded to the participant identity, testing conditions and the imaging site. Additionally we monitored haemoglobin concentration and haematocrit data to see if we could support or refute mechanisms of altered density relating to vessel recruitment. Repeated sets of paired values were compared using Kruskall Wallis Analysis of Variance tests, whilst comparisons of values between sites was by related samples Wilcoxon Signed Rank Test. Correlation between different variables was performed using Spearman's rank correlation coefficient, and concordance between analysing investigators using intra-class correlation coefficient. There was a significant increase in capillary density from London on ascent to high altitude; median capillaries per field of view area increased from 22.8 to 25.3 ( $p=0.021)$. There was a further increase in vessel density during the six weeks spent at altitude (25.3 to 32.5, $p=0.017)$. Moreover, vessel density remained high on descent to

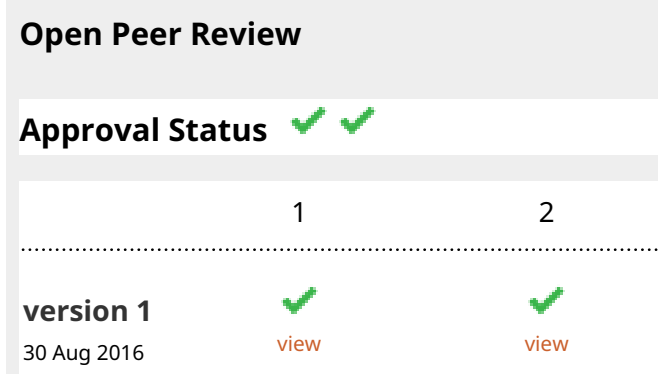

1. Sam Hutchings, Kings College London University, London, UK

2. Matthias Hilly, University Hospital of Zurich,

Zurich, Switzerland

Any reports and responses or comments on the article can be found at the end of the article. 
Kathmandu (31.0 capillaries per field of view area), despite a significant decrease in haemoglobin concentration and haematocrit. Using a simplified technique, we have demonstrated an increase in capillary density on early and sustained exposure to hypobaric hypoxia at thigh altitude, and that this remains elevated on descent to normoxia. The technique is simple, reliable and reproducible.

\section{Keywords}

Capillaries, Microcirculation, Altitude, Microscopy, Oxygen

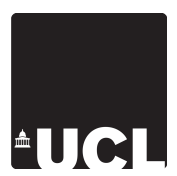

This article is included in the University College

London collection.

Corresponding author: Edward Gilbert-Kawai (e.gilbert@ucl.ac.uk)

Competing interests: Braedius Medical, a company owned by a relative of Can Ince, has developed and designed a hand held microscope called CytoCam-IDF imaging. Can Ince has no financial relation with Braedius Medical of any sort; he never owned shares, or received consultancy or speaker fees from Braedius Medical.

Grant information: Xtreme Everest 2 was supported by the Royal Free Hospital NHS Trust Charity, the Special Trustees of University College London Hospital NHS Foundation Trust, the Southampton University Hospital Charity, the UCL Institute of Sports Exercise and Health, The London Clinic, University College London, University of Southampton, Duke University Medical School, the United Kingdom Intensive Care Society, the National Institute of Academic Anaesthesia, the Rhinology and Laryngology Research Fund, The Physiological Society, Smiths Medical, Deltex Medical, Atlantic Customer Solutions and the Xtreme Everest 2 volunteer participants who trekked to Everest Base Camp. Some of this work was undertaken at University College London Hospital- University College London Biomedical Research Centre, which received a proportion of funding from the United Kingdom Department of Health's National Institute for Health Research Biomedical Research Centers funding scheme. Some of this work was undertaken at University Hospital SouthamptonUniversity of Southampton Respiratory Biomedical Research Unit, which received a proportion of funding from the United Kingdom Department of Health's National Institute for Health Research Biomedical Research Units funding scheme.

The funders had no role in study design, data collection and analysis, decision to publish, or preparation of the manuscript.

Copyright: @ 2016 Gilbert-Kawai E et al. This is an open access article distributed under the terms of the Creative Commons Attribution License, which permits unrestricted use, distribution, and reproduction in any medium, provided the original work is properly cited. Data associated with the article are available under the terms of the Creative Commons Zero "No rights reserved" data waiver (CC0 1.0 Public domain dedication).

How to cite this article: Gilbert-Kawai E, Coppel J, Hennis P et al. Changes in labial capillary density on ascent to and descent from high altitude [version 1; peer review: 2 approved] F1000Research 2016, 5:2107 https://doi.org/10.12688/f1000research.7649.1

First published: 30 Aug 2016, 5:2107 https://doi.org/10.12688/f1000research.7649.1 


\begin{tabular}{ll}
\multicolumn{2}{l}{ List of Abbreviations } \\
EBC & Everest Base Camp \\
FOV & Field of view area \\
{$[\mathrm{Hb}]$} & Haemoglobin concentration \\
$\mathrm{Hct}$ & Haematocrit \\
$\mathrm{IDF}$ & Incident Dark Field \\
$\mathrm{KTM}$ & Kathmandu \\
$\mathrm{LON}$ & London \\
$\mathrm{SpO}_{2}$ & Peripheral oxygen saturation
\end{tabular}

\section{Introduction}

The physiological processes involved in acclimatisation to high altitude attempt to maintain adequate oxygen delivery as the partial pressure of oxygen decreases. Traditionally, research has concentrated on global haemodynamics and the macrocirculation, variables such as cardiac output ${ }^{1}$, oxygen saturations ${ }^{2}$ and haemoglobin concentration $[\mathrm{Hb}]^{3}$. Far fewer studies have focused on the microcirculation, which regulates blood flow to match microregional oxygen demand. Disruption of microvascular blood flow could explain a failure of acclimatisation in some individuals as well as the well-documented exercise limitation that occurs at altitude despite normalisation of systemic oxygen delivery ${ }^{4}$. The precise role of the microcirculation in acclimatisation to hypoxia, however, remains unclear.

Teleological reasoning would suggest that increasing capillary density could provide a means to augment oxygen flux and tissue oxygenation through a reduction in the inter-capillary distance ${ }^{5}$. Whilst plausible, data on this theory remains contradictory, though this may in part relate to the dissimilar tissues observed. In human skeletal muscle biopsy samples previously exposed to hypobaric hypoxia, no evidence of neovascularisation has been demonstrated $^{6-9}$. Interestingly, in each instance whereby the capillary density was initially thought to increase, no change in the capillary-to-fibre ratio was observed. The perceived rise in capillary density were therefore interpreted as being secondary occurrences in response to a reduction in skeletal muscle mass. Conversely, an increase in the density of sublingual microcirculatory vessels to $>25 \mu \mathrm{m}$ was demonstrated on ascent to high altitude $^{10,11}$, a response that was further amplified after prolonged exposure to hypoxia ${ }^{10}$. In this instance, what remains to be determined is whether the observed changes in vessel density are due to microvascular recruitment secondary to increased blood viscosity (and thus quickly reversible), or neovascularization (which is likely to be sustained). Moreover, the question of what happens to vessel density following re-exposure to normoxia remains to be elucidated.

We therefore piloted a novel modification of a previously described technique for calculating changes in capillary density ${ }^{12,13}$ on ten individuals, to see if we could firstly support or refute previous findings on ascent to high altitude, and secondly see if the changes observed persist on descent. Additionally we monitored haemoglobin concentration and haematocrit data to see if we could support of refute mechanisms of altered density relating to vessel recruitment.

\section{Methods}

The study was undertaken as part of the Xtreme Everest 2 research expedition (XE2) ${ }^{14}$. The study design, risk management plan and protocol were approved (in accordance with the declaration of Helsinki) both by the University College London Committee and the Ethics of Non-National Health Service Human Research, and the Nepal Health Research Council (Reg no. 139/2012). Written consent was obtained from all participants. Baseline images of the labial capillaries were initially obtained from ten individuals in London (LON) (35m) in December 2012 and January 2013. Sequential images were taken after an 11 day ascent to Everest Base Camp (EBC-early) (5300m), then after 6 weeks residence at Everest Base Camp (EBC-late), and finally on descent, over 5 days, to Kathmandu (KTM) (1300m) in May 2013.

Images were obtained using a CytoCam-IDF video microscope (Braedius, Medical BV, Netherlands). This new device is based on the principle of Incident Dark Field (IDF) imaging, which uses polarized green light (wavelength $548 \mathrm{~nm}$ ) produced from LEDs to visualize, in real time, the sublingual microvasculature. Its high resolution imaging sensor (14 Mpixel) allows for a 50\% increase in optical resolution (300 lines $/ \mathrm{mm}$ ) compared to previous Sidestream Dark Field imaging devices, and it generates a far larger field of view. With the participant lying in the supine position having rested for a minimum of 10 minutes, the CytoCam-IDF device's probe was introduced into their mouth and placed on the mucosal surface of the inner lip. Once a suitable image was visualised on the screen of the CytoCam-IDF monitor, (Figure 1), 1 second of digital video footage was recorded.

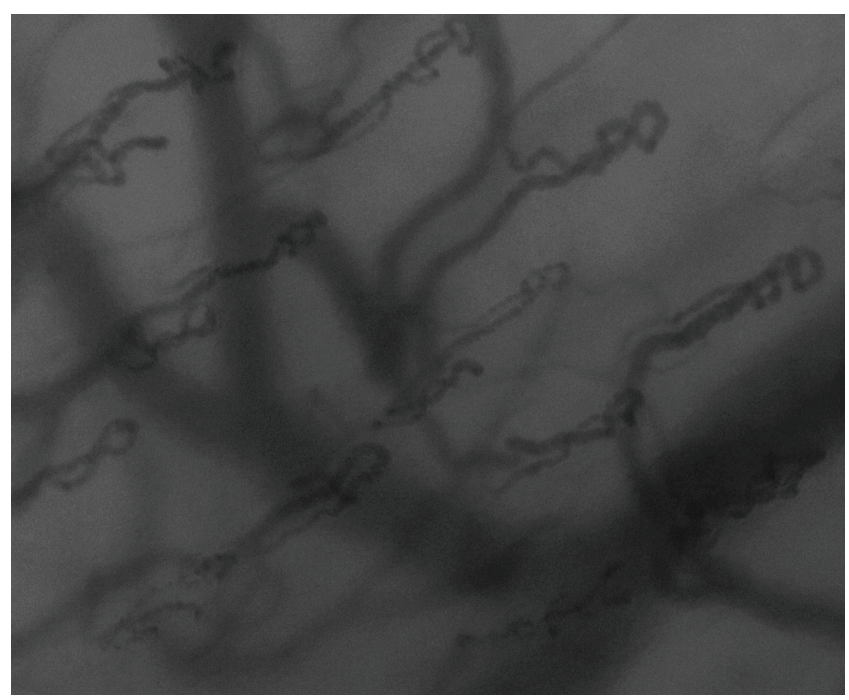

Figure 1. An example of a labial capillary density image. 
This process was conducted on all four lip quadrants (right upper lip, left upper lip, right lower lip, left lower lip), and at each quadrant four separate videos were acquired. Two trained investigators (EGK, PH) obtained all the data.

To determine capillary density, analysis was conducted offline by two independent investigators blinded to the participant identity, the testing conditions and the imaging site (EGK, JC). Using the company's own video software (CytoCamTools V1, Braedius, Netherlands), a single still frame was projected on the computer screen and the number of capillary loops per image frame was counted manually. Partly visualised capillaries were included if the observer was assured that the vessel was a capillary due to its morphology. Subsequently, the mean capillary density was calculated from the four images obtained in each lip quadrant, and from these four results, the mean total lip density obtained. Capillary density was defined as the number of capillaries counted per field of view area (FOV), which equates to $1.79 \mathrm{~mm}^{2}$. The haemoglobin concentration ([Hb]) (Hemocue AB, Hemocue, Sweden) and haematocrit (Hct) (Sigma 1-14 microcentrifuge, Sigma, Germany) were obtained from whole blood samples, and peripheral arterial oxygen saturation $\left(\mathrm{SpO}_{2}\right)$ measured (Nonin Onyx 9500, Nonin Medical Inc, Minnesota, USA) on the same days as microcirculatory imaging was performed.

\section{Statistical analysis}

As data were not normally distributed, they were described by median and interquartile range. Repeated sets of paired values were compared using Kruskall Wallis ANOVA, whilst comparisons of values between LON baseline and other sites was by Wilcoxon Signed Rank Test. Correlation between different variables was performed using Spearman's rank correlation coefficient, and concordance between analysing investigators using intra-class correlation coefficient. All statistical analysis was undertaken on SPSS version 21 (SPSS Inc., Chicago, IL, USA), and a P value of $<0.05$ was taken to indicate statistical significance.

\section{Results}

Dataset 1. IDF values

http://dx.doi.org/10.5256/f1000research.7649.d134021

The number of loop capillaries seen per field of view

Dataset 2. Physiological values

http://dx.doi.org/10.5256/f1000research.7649.d134022

The haemoglobin, haematocrit and peripheral oxygen saturations at each laboratory.

CytoCam-IDF imaging was conducted on all ten individuals on the first two occasions, however only eight individuals had data captured on descent. No problems were encountered with the device or image acquisition. Mean laboratory barometric pressure and mean temperature for each location is shown in Table 1.
Table 1. Mean (standard deviation) atmospheric pressure and temperature at each laboratory.

\begin{tabular}{|l|l|l|l|}
\hline Site & $\begin{array}{l}\text { Atmospheric } \\
\text { Pressure }(\mathbf{k P a})\end{array}$ & $\begin{array}{l}\text { Temperature } \\
\left({ }^{\circ} \mathbf{C}\right)\end{array}$ & $\begin{array}{l}\text { Humidity } \\
(\%)\end{array}$ \\
\hline London & $100.6(0.2)$ & $16.9(1.8)$ & $35.4(6.5)$ \\
\hline $\begin{array}{l}\text { Everest Base } \\
\text { Camp }\end{array}$ & $53.0(0.2)$ & $12.9(8.2)$ & $37.8(17.5)$ \\
\hline Kathmandu & $86.8(0.4)$ & $23.8(3.4)$ & $47.4(15.7)$ \\
\hline
\end{tabular}

Changes in labial capillary density are shown in Figure 2. Compared with LON (median 22.8 capillaries per field of view area (20.7-26.8)), capillary density was significantly increased at EBC-early 25.3 (24.5-30.6; p=0.021), EBC-late 32.5, (28.4-36.63; $\mathrm{p}=0.012)$, and on descent in KTM $31.0(24.0-35.13 ; \mathrm{P}=0.017)$. Between EBC-early and EBC-late, capillary density increased significantly $(\mathrm{p}=0.017)$, however there was no significant decline in density between EBC-late and KTM $(p=0.069)$.

Changes in [Hb], Hct and $\mathrm{SpO}_{2}$ at each site are shown in Table 2. There was a significant increase in $[\mathrm{Hb}]$ between LON and EBCearly $(p=0.007)$, and EBC-early and EBC-late $(p=0.011)$, and a decrease between EBC-late and KTM $(p=0.008)$. There was also a significant increase in Hct between LON and EBC-early ( $\mathrm{p}=0.007)$, and $\mathrm{EBC}$-late and $\mathrm{KTM}(\mathrm{p}=0.012)$, but no significant change between EBC-early and EBC-late $(\mathrm{p}=0.191)$. Between the sites on ascent, the increase in vessel density demonstrated an inverse relationship with the $\mathrm{SpO}_{2}$, however at each altitude there was no correlation between vessel density and [Hb], Hct or $\mathrm{SpO}_{2}$.

To assess whether an image capture time of 1 second was indicative of that captured over longer periods of time, we obtained 30 seconds of footage from four individuals at two different locations. From this we randomly selected one frame per five seconds of footage, and counted the number of capillaries per field of view area. The values of these may be seen in Table 3, as too can the mean and standard deviations for each set of frames, the latter of which demonstrates a highest value of only 0.52 capillaries per field of view area.

\section{Discussion}

This study demonstrates for the first time, persistence of in vivo sublingual microvascular density increase on re-exposure to normoxia after a prolonged period of hypobaric hypoxia at high altitude. We utilised an infrequently used imaging and analysis technique that we had purposefully adapted to suit our needs, and found our data aligned with previously published work on blood vessel density at altitude ${ }^{10}$.

Using the data obtained from corresponding blood samples, it is possible to speculate on the adaptive processes occurring at each measurement point. As previously described, we observed a significant rise in $[\mathrm{Hb}](14.5 \mathrm{~g} / \mathrm{dl}$ to $16.4 \mathrm{~g} / \mathrm{dl} ; \mathrm{p}=0.007)$ and Hct $(44 \%$ 


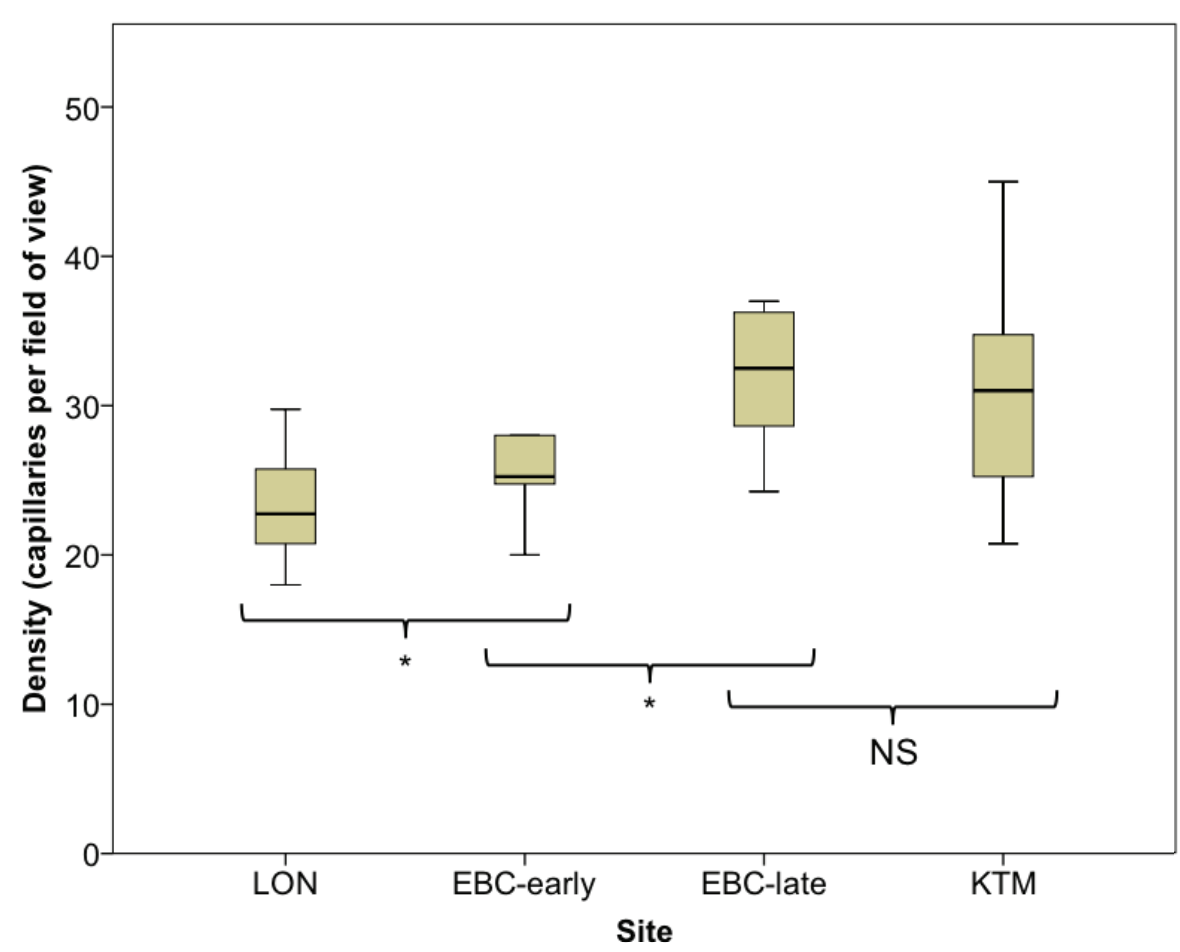

Figure 2. Box-whisker plots of labial capillary density on ascent from London to Everest Base Camp, after six weeks at Everest Base Camp, and on descent to Kathmandu.

\begin{tabular}{|c|c|c|c|}
\hline Site & $\begin{array}{l}\text { Hemoglobin } \\
\text { concentration }(\mathrm{g} / \mathrm{dl})\end{array}$ & Hematocrit (\%) & $\begin{array}{l}\text { Oxygen } \\
\text { saturation (\%) }\end{array}$ \\
\hline London & $14.5(13.5-15.3)$ & $44.0(41.5-47.5)$ & $99(98-100)$ \\
\hline $\begin{array}{l}\text { Everest Base } \\
\text { Camp - early }\end{array}$ & $16.4(15.7-17.2)$ & $52.0(51.5-56.3)$ & $81(79-86)$ \\
\hline $\begin{array}{l}\text { Everest Base } \\
\text { Camp - late }\end{array}$ & $18.3(17.1-19.7)$ & $56.0(51.0-61.5)$ & $88(85-91)$ \\
\hline Kathmandu & $16.0(14.0-17.0)$ & $50.0(46.5-55.0)$ & $99(99-100)$ \\
\hline
\end{tabular}

Table 3. Number of capillaries counted per field of view area from one randomly selected frame per five seconds of footage, with mean and standard deviation demonstrated.

\begin{tabular}{|l|l|l|l|l|l|l|l|l|l|}
\hline Code & Site & $\begin{array}{l}\text { Frame 1 } \\
\mathbf{( 0 - 5} \mathbf{~ s )}\end{array}$ & $\begin{array}{l}\text { Frame 2 } \\
\mathbf{( 5 - 1 0 ~ s )}\end{array}$ & $\begin{array}{l}\text { Frame 3 } \\
\mathbf{( 1 0 - 1 5} \mathbf{~ s )}\end{array}$ & $\begin{array}{l}\text { Frame 4 } \\
\mathbf{( 1 5 - 2 0 ~ s )}\end{array}$ & $\begin{array}{l}\text { Frame 5 } \\
\mathbf{( 2 0 - 2 5 ~ s )}\end{array}$ & $\begin{array}{l}\text { Frame 6 } \\
\mathbf{( 2 5 - 3 0 ~ s )}\end{array}$ & Mean & SD \\
\hline 1 & LON & 30 & 30 & 30 & 30 & 30 & 30 & 30.0 & 0.00 \\
\hline 2 & LON & 24 & 25 & 24 & 24 & 24 & 25 & 24.3 & 0.52 \\
\hline 3 & KTM & 27 & 27 & 27 & 27 & 26 & 27 & 26.8 & 0.41 \\
\hline 4 & KTM & 22 & 23 & 23 & 23 & 23 & 22 & 22.7 & 0.52 \\
\hline
\end{tabular}

$\mathrm{S}=$ seconds; $\mathrm{SD}=$ standard deviation 
to $52 \% ; \mathrm{p}=007))$ on ascent to altitude. Whilst this polycythaemia increases arterial oxygen content, blood viscosity also rises, altering its rheology. Under normal physiological conditions, a considerable proportion of the microcirculation is thought to be 'unrecruited', acting as a reservoir for times of increased metabolic needs ${ }^{15}$. As Hct rises, these reserve vessels are recruited, and microvascular density increases, along with functional capillary density ${ }^{15-18}$. Thus a secondary benefit to increased Hct is achieved; a reduction in the diffusion distance from capillaries to mitochondria. Importantly however, it should be noted that in normal capillary Hct is generally $50 \%$ less than systemic Hct owing to the streamlined blood flow in narrow capillaries ${ }^{19}$. The effect of hypoxia on this association is unknown. Whether or not neovascularisation had occurred on arrival at high altitude is difficult to say, although due to the short time between measurement points the chances of this being the case are low ${ }^{20}$.

After 6 weeks spent at altitude, a further, and far greater, increase in vessel density was apparent; EBC-early 25.3 capillaries per field of view area, EBC-late $32.5(\mathrm{p}=0.017)$. Over the same time period, $[\mathrm{Hb}]$ had significantly risen, whilst Hct had not. As Hct is a more reliable indicator of viscosity between the two variables ${ }^{21}$, it seems unlikely that further recruitment of the microvasculature had occurred, yet it is plausible that neovascularisation had. Increased levels of vascular endothelial growth factor (VEGF) have been detected in subjects ascending to high altitude ${ }^{22}$; its role in angiogenesis perhaps explaining the observed rise in microvascular density ${ }^{10}$. Such adaptations lead to improved tissue oxygenation by a reduction of the inter-capillary distance, whilst maintaining a sufficiently low, and thus fluid Hct to permit flow of red blood cells in the microvasculature.

On descent to a lower altitude (KTM) there was no significant fall in microvascular density when compared to EBC-late $(\mathrm{p}=0.069)$, however, a much greater number of vessels (36\% increase) was evident when compared with baseline testing in LON. Whilst vessel density was thus unaltered on descent, over the same time point $[\mathrm{Hb}]$ and Hct values significantly declined $(\mathrm{p}=0.012)$. When compared to the original LON values, Hct on descent to KTM was significantly higher $(44.0 \%$ and $50.0 \%$ respectively $(\mathrm{p}=0.011)$ ), however, $[\mathrm{Hb}]$ was not $(14.5$ and $16.0 \mathrm{~g} / \mathrm{dl}(\mathrm{p}=0.052))$. Teasing apart the relative contributions of vessel recruitment and neovascularisation to the observed changes in sublingual microcirculatory density is challenging. Whilst the failure of vessel density to return to baseline after descent suggests some neovascularisation, neither [Hb] nor Hct had normalised at the time of the final readings so a raised blood viscosity could perhaps be maintaining a heightened level of capillary recruitment. A combination of the two processes would make sense as continually increasing $[\mathrm{Hb}]$ to improve oxygen delivery would eventually be counter productive. Indeed in Tibetans, who have been exposed to environmental hypoxia for many generations, there is a clear reduction in $[\mathrm{Hb}]$ compared to populations who have been exposed to these conditions for less time $^{23-26}$. This suggests Tibetans utilize alternative long-term strategies for chronic adaptation to hypobaric hypoxia, ones that do not rely on maintaining a high $[\mathrm{Hb}]$. It is plausible that one such means would be to increase their capillary density.
Technique and analysis

The use of the described methodology was also novel. A similar technique has been used twice previously; once in the assessment of coronary artery disease in diabetes ${ }^{13}$ and the other in a study investigating hypertension and rarefaction during treatment with Telatinib ${ }^{12}$. In these instances, data capture involved recording sublingual images for 1 minute $^{13}$ or 30 seconds $^{12}$ per quadrant, however we altered this time period by using an extremely short capture phase for data acquisition ( $<1$ second). Crucially, this allowed us to readily obtain snap shot images to reveal data about microvasculature density, whilst avoiding concerns surrounding probe and patient movement, in addition to issues relating to pressure artefact. Analysis was rapid, simple and reproducible; in this study it had an observer mean intra-class correlation coefficient of $0.91(95 \%$ CI $0.84-0.96)$. Previously no difference in capillary density was observed in ten individuals between lip quadrants, and the reproducibility of the technique to determine capillary density was moderate to high with a coefficient of variation of $4.6 \%{ }^{12}$. Of note, the technique does not allow assessment of microvascular flow, nor does it yield information on heterogeneity of microvascular blood flow, however, we propose it to be a robust method for the assessment of labial vessel density that could be conducted after only a short user training period.

\section{Study limitations}

The small number of participants used in this study could be considered a study limitation. As we were both employing a newlyadapted data acquisition technique, and using a novel device at altitude, no power calculation was performed. This therefore increases the risk of a type 2 error. Other limiting factors include the environmental considerations associated with high altitude research in a remote field environment. These include fluctuations in laboratory temperature, humidity (Table 1) and participant hydration status, all factors that may alter microvascular blood flow and density. Attempts were made to limit these potential confounding factors by performing CytoCam-IDF imaging at the same time of day in heated purpose-built laboratories, and encouraging participants to maintain a good state of hydration. Previous studies at altitude have also raised concerns over the development of tissue oedema ${ }^{10,11}$ that can occur on ascent to altitude ${ }^{27}$. Whilst this could potentially reduce image quality and lead to false measurements of flow and density, our IDF camera provided us with a depth of focus reading, thus allowing us to confirm that we were recording at the same depth under the tongue on each time point. Finally, we have discussed alterations in capillary or vessel density. It is important however to clarify this nomenclature. IDF imaging cannot image blood vessels directly but rather uses the fact that polarized green light is optimally absorbed by red blood cells within the microvasculature regardless of oxygenation status. Absorption of light by haemoglobin, but not by surrounding tissues, therefore creates a distinct contrast of dark and light colour respectively, and red blood cells moving through the mucosal microcirculation thus appear as dark globules moving along the axis of flow. All vessels visualized are therefore only seen if they contain erythrocytes. The variables measured by IDF imaging (and its precursor SDF imaging) include a measure of total vessel density (TVD) and perfused vessel density (PVD) ${ }^{28}$. 
A distinction is made between the two depending on the speed of red blood cell flow within the observed vessels. TVD includes vessels which contain erythrocytes flowing at any velocity (or even at standstill), whilst PVD only includes vessels with continuously moving erythrocytes. As we cannot measure erythrocyte velocity with this simplified method, our observations therefore describe the TVD.

\section{Conclusions}

This study demonstrated an increase in sublingual microvascular vessel density on early and sustained exposure to hypobaric hypoxia; and, for the first time, that no significant change in vessel density occurred on immediate descent. The technique used to capture the images provided a rapid and reliable means for assessing changes in vessel density, and could be applied in future studies of microcirculatory vessel density. Further research in this area may allow a more complete comprehension of the multidimensional response to sustained hypoxia that occurs during pathophysiological situations.

\section{Data availability}

F1000Research: Dataset 1. IDF values, 10.5256/f1000research.7649. $\mathrm{d} 134021^{29}$

F1000Research: Dataset 2. Physiological values, 10.5256/ f1000research.7649.d134022 30

\section{Author contributions}

E G-K: design of study, collection of data, analysis of data, writing manuscript

JC: collection of data, analysis of data, writing manuscript

PH: analysis of data, writing manuscript

MG: design of study, writing manuscript

CI: design of study, writing manuscript

DM: design of study, analysis of data, writing manuscript

All authors have seen and agreed to the final content of the manuscript

\section{Competing interests}

Braedius Medical, a company owned by a relative of Can Ince, has developed and designed a hand held microscope called CytoCam-IDF imaging. Can Ince has no financial relation with Braedius Medical of any sort; he never owned shares, or received consultancy or speaker fees from Braedius Medical.

\section{Grant information}

Xtreme Everest 2 was supported by the Royal Free Hospital NHS Trust Charity, the Special Trustees of University College London Hospital NHS Foundation Trust, the Southampton University Hospital Charity, the UCL Institute of Sports Exercise and Health, The London Clinic, University College London, University of Southampton, Duke University Medical School, the United Kingdom Intensive Care Society, the National Institute of Academic Anaesthesia, the Rhinology and Laryngology Research Fund, The Physiological Society, Smiths Medical, Deltex Medical, Atlantic Customer Solutions and the Xtreme Everest 2 volunteer participants who trekked to Everest Base Camp.

Some of this work was undertaken at University College London Hospital-University College London Biomedical Research Centre, which received a proportion of funding from the United Kingdom Department of Health's National Institute for Health Research Biomedical Research Centers funding scheme. Some of this work was undertaken at University Hospital Southampton-University of Southampton Respiratory Biomedical Research Unit, which received a proportion of funding from the United Kingdom Department of Health's National Institute for Health Research Biomedical Research Units funding scheme.

The funders had no role in study design, data collection and analysis, decision to publish, or preparation of the manuscript.

\section{Acknowledgements}

Xtreme Everest 2 is a research project coordinated by the Caudwell Xtreme Everest Hypoxia Research Consortium, collaboration between the UCL Centre for Altitude, Space, and Extreme Environment Medicine, the Centre for Human Integrative Physiology at the University of Southampton and the Duke University Medical Centre. Membership, roles and responsibilities of the Xtreme Everest 2 Research Group can be found at www. xtreme-everest.co.uk/team.
1. Wagner PD: Reduced maximal cardiac output at altitude--mechanisms and significance. Respir Physiol. 2000; 120(1): 1-11. PubMed Abstract | Publisher Full Text

2. Stoneham MD, Pethybridge RJ: Acclimatization to altitude: effects on arterial oxygen saturation and pulse rate during prolonged exercise at altitude. $J R$ Nav Med Serv. 1993; 79(1): 3-9. PubMed Abstract

3. Pugh LG: Blood volume and haemoglobin concentration at altitudes above 18,000 ft. (5500 m). J Physiol. 1964; 170(2): 344-354. PubMed Abstract | Publisher Full Text | Free Full Text
4. Levett DZ, Fernandez BO, Riley HL, et al:: The role of nitrogen oxides in human adaptation to hypoxia. Sci Rep. 2011; 1: 109. PubMed Abstract | Publisher Full Text | Free Full Text

5. Hochachka PW, Stanley C, Merkt J, et al:: Metabolic meaning of elevated levels of oxidative enzymes in high altitude adapted animals: an interpretive hypothesis. Respir Physiol. 1983; 52(3): 303-313. PubMed Abstract | Publisher Full Text

6. Hoppeler $\mathrm{H}$, Kleinert E, Schlegel C, et al:: Morphological adaptations of human skeletal muscle to chronic hypoxia. Int J Sports Med. 1990; 11(Suppl 1): S3-S9. PubMed Abstract | Publisher Full Text 
7. MacDougall JD, Green HJ, Sutton JR, et al:: Operation Everest II: structural adaptations in skeletal muscle in response to extreme simulated altitude. Acta Physiol Scand. 1991; 142(3): 421-427.

PubMed Abstract | Publisher Full Text

8. Lundby $\mathrm{C}$, Pilegaard $\mathrm{H}$, Andersen $\mathrm{JL}$, et al:: Acclimatization to $4100 \mathrm{~m}$ does not change capillary density or mRNA expression of potential angiogenesis regulatory factors in human skeletal muscle. J Exp Biol. 2004; 207(pt 22): 3865-3871.

PubMed Abstract | Publisher Full Text

9. Mizuno M, Savard GK, Areskog NH, et al: Skeletal muscle adaptations to prolonged exposure to extreme altitude: a role of physical activity? High Alt Med Biol. 2008; 9(4): 311-317.

PubMed Abstract | Publisher Full Text

10. Martin DS, Goedhart $P$, Vercueil $A$, et al.: Changes in sublingual microcirculatory flow index and vessel density on ascent to altitude. Exp Physiol. 2010; 95(8): 880-891.

PubMed Abstract | Publisher Full Text

11. Martin DS, Ince $C$, Goedhart $P$, et al:: Abnormal blood flow in the sublingual microcirculation at high altitude. Eur J Appl Physiol. 2009; 106(3): 473-478. PubMed Abstract | Publisher Full Text | Free Full Text

12. Steeghs N, Gelderblom H, Roodt JO, et al.: Hypertension and rarefaction during treatment with telatinib, a small molecule angiogenesis inhibitor. Clin Cancer Res. 2008; 14(11): 3470-3476.

PubMed Abstract | Publisher Full Text

13. Djaberi R, Schuijf JD, de Koning EJ, et al:: Non-invasive assessment of microcirculation by sidestream dark field imaging as a marker of coronary artery disease in diabetes. Diab Vasc Dis Res. 2013; 10(2): 123-134. PubMed Abstract | Publisher Full Text

14. Martin DS, Gilbert-Kawai E, Levett DZh, et al.: Xtreme Everest 2: unlocking the secrets of the Sherpa phenotype? Extrem Physiol Med. 2013; 2(1): 30. PubMed Abstract | Publisher Full Text | Free Full Text

15. Parthasarathi K, Lipowsky HH: Capillary recruitment in response to tissue hypoxia and its dependence on red blood cell deformability. Am J Physiol. 1999; 277(6 Pt 2): H2145-H2157. PubMed Abstract

16. Genzel-Boroviczény $\mathrm{O}$, Christ F, Glas V: Blood transfusion increases functional capillary density in the skin of anemic preterm infants. Pediatr Res. 2004; 56(5): 751-755.

PubMed Abstract | Publisher Full Text

17. Sakr $\mathrm{Y}$, Chierego M, Piagnerelli M, et al.: Microvascular response to red blood cell transfusion in patients with severe sepsis. Crit Care Med. 2007; 35(7): 1639-1644.

PubMed Abstract | Publisher Full Text
18. Yuruk K, Almac E, Bezemer R, et al:: Blood transfusions recruit the microcirculation during cardiac surgery. Transfusion. 2011; 51(5): 961-967. PubMed Abstract | Publisher Full Text

19. Duling BR, Klitzman B: Local control of microvascular function: role in tissue oxygen supply. Annu Rev Physiol. 1980; 42: 373-382.

PubMed Abstract | Publisher Full Text

20. Lindeboom JA, Mathura KR, Aartman IH, et al:: Influence of the application of platelet-enriched plasma in oral mucosal wound healing. Clin Oral Implants Res. 2007; 18(1): 133-139.

PubMed Abstract | Publisher Full Text

21. Pries AR, Secomb TW, Gaehtgens P: Biophysical aspects of blood flow in the microvasculature. Cardiovasc Res. 1996; 32(4): 654-667.

PubMed Abstract | Publisher Full Text

22. Walter R, Maggiorini M, Scherrer $\mathrm{U}$, et al:: Effects of high-altitude exposure on vascular endothelial growth factor levels in man. Eur J Appl Physiol. 2001; 85(1-2): 113-117.

PubMed Abstract | Publisher Full Text

23. Adams WH, Strang LJ: Hemoglobin levels in persons of tibetan ancestry living at high altitude. Proc Soc Exp Biol Med. 1975; 149(4): 1036-1039.

PubMed Abstract | Publisher Full Text

24. Beall $C M$, Reichsman $A B$ : Hemoglobin levels in a Himalayan high altitude population. Am J Phys Anthropol. 1984; 63(3): 301-306. PubMed Abstract | Publisher Full Text

25. Samaja M, Veicsteinas A, Cerretelli P: Oxygen affinity of blood in altitude Sherpas. J Appl Physiol Respir Environ Exerc Physiol. 1979; 47(2): 337-341. PubMed Abstract

26. Wu T, Wang X, Wei C, et al:: Hemoglobin levels in Qinghai-Tibet: different effects of gender for Tibetans vs. Han. J Appl Physiol (1985). 2005; 98(2): 598-604. PubMed Abstract | Publisher Full Text

27. Maggiorini $\mathrm{M}, \mathrm{Bühler} \mathrm{B}$, Walter $\mathrm{M}$, et al:: Prevalence of acute mountain sickness in the Swiss Alps. BMJ. 1990; 301(6756): 853-855. PubMed Abstract | Publisher Full Text | Free Full Text

28. De Backer D, Hollenberg S, Boerma C, et al:: How to evaluate the microcirculation: report of a round table conference. Crit Care. 2007; 11(5): R101. PubMed Abstract | Publisher Full Text | Free Full Text

29. Gilbert-Kawai E, Coppel J, Phillip H, et al.: Dataset 1 in: Changes in labial capillary density on ascent to and descent from high altitude. F1000Research. 2016. Data Source

30. Gilbert-Kawai E, Coppel J, Phillip H, et al:: Dataset 2 in: Changes in labial capillary density on ascent to and descent from high altitude. F1000Research. 2016.

Data Source 


\section{Open Peer Review}

\section{Current Peer Review Status:}

\section{Version 1}

Reviewer Report 28 September 2016

https://doi.org/10.5256/f1000research.8238.r15955

(C) 2016 Hilly M. This is an open access peer review report distributed under the terms of the Creative Commons Attribution License, which permits unrestricted use, distribution, and reproduction in any medium, provided the original work is properly cited.

\section{Matthias Hilly}

Medical Intensive Care Unit, University Hospital of Zurich, Zurich, Switzerland

The authors report on the use of a relatively novel method to determine capillary density during acute and chronic exposure to hypobaric hypoxia. Previously reported results of an increase in capillary density during acclimatization are confirmed, but it is for the first time demonstrated that upon immediate descent some changes persist.

Overall, this is a well-conducted study that adds to the current knowledge base of microcirculatory changes during adaptation to hypobaric hypoxia, and provides an innovative approach to vessel density measurement.

Specific comments:

\section{Introduction}

In the introduction the absence of neovascularization in muscle samples during adaptation to high altitude is discussed. It is however also known that mitochondrial density increases during this process (PMID 26339730). The authors may want to include this in the discussion about capillaryto-fibre ratio, the mitochondria arguably representing the circulation's endpoint.

\section{Methods}

The KTM time point seems difficult to me for use as a "post-hypoxia" measurement, since it is not comparable to the LON baseline. This is not a severe limitation since "immediate descent" was one of the study endpoints rather that a comparison to the initial (LON) baseline. I still suggest mentioning this in the limitations.

Microcirculation capture time is very short (1 sec). I am not sure if the analysis in four subjects given in table 3 is sufficient support for the use of much shorter capture intervals than recommended by current consensus guidelines. This could be discussed in more detail in the 
limitations.

$\mathrm{Hb}$ and Hematocrit values, as well as $\mathrm{SpO}_{2}$ were determined "on the same day as microcirculatory imaging was performed". Given the influence of hydration status changes throughout a day, especially in a mountain setting, either specify the time frame more clearly or mention this time relation in the limitations.

\section{Results}

Figure 2: It is unclear to me what the results of the Kruskal-Wallis ANOVA described in the methods section were for vessel density measurements, consider mentioning these in the results section. Further, are the $P$ values given in the text references to Wilcoxon Signed Rank tests as mentioned in the methods section? Consider describing these tests as post-hoc analysis for the non-parametric ANOVA. And if so, was a correction for multiple testing applied (Bonferroni, or one of the newer algorithms)? Please describe this more clearly.

It is mentioned that at each altitude there was no correlation between vessel density and $\mathrm{Hb}, \mathrm{Hct}$ or $\mathrm{SpO}_{2}$. In the methods section it is stated that Spearman's rank correlation coefficient was calculated. Consider adding correlation coefficients and $P$ values to the results section to provide the readers some insight into the data.

In addition to $\mathrm{Hb}, \mathrm{Hct}$ and $\mathrm{SpO}_{2}$ given in Table 2, it would be of interest to know more about the subjects' physiologic parameters, such as blood pressure, cardiac output and even RV/RA including a discussion about the changes in macrocirculation in relation to the changes in microcirculation.

\section{Discussion}

Given borderline significance $(p=0.069)$ for a decrease in vessel density from EBC-late to KTM and the lack of a power calculation, as well as the lack of real comparability to the initial (LON) baseline it is somewhat difficult to argue that there really was no change between EBC-late and KTM. This is discussed in the discussion to some extent, but it should be stated more clearly that a verification of these results is needed in the future.

The method for vessel density estimation used in this study differs from the effective calculation of total vessel density (TVD), being the total length of small vessels divided by the surface area covered in the recording, that is recommended by current consensus guidelines. Please discuss the relationship between vessel density as measured in this study with vessel density as assessed by TVD, and potential confounders.

Competing Interests: No competing interests were disclosed.

\section{I confirm that I have read this submission and believe that I have an appropriate level of expertise to confirm that it is of an acceptable scientific standard.}

Reviewer Report 14 September 2016

https://doi.org/10.5256/f1000research.8238.r16269 
(C) 2016 Hutchings S. This is an open access peer review report distributed under the terms of the Creative Commons Attribution License, which permits unrestricted use, distribution, and reproduction in any medium, provided the original work is properly cited.

\section{Sam Hutchings}

Department of Critical Care, Kings College London University, London, UK

Edward Gilbert-Kawai and colleagues involved in the Xtreme Everest 2 study report further work on the effects of altitude and hypoxaemia on the microcirculation. They describe a technique for rapidly measuring microcirculatory capillary density, using a method of counting the number of capillary loops in the buccal mucosa of healthy volunteers at sea level, progressive altitude acclimatisation and descent. They also report systemic haemoglobin and haematocrit values in an attempt to elucidate whether changes in microcirculatory parameters are paralleled by changes in blood viscosity. Their results show, in line with previous work, that microcirculatory vessel density increases after prolonged exposure to hypoxic conditions. However, they also show that there is some persistence of this effect on partial descent. The authors pose a question as to whether this increased vessel density is due to neo-vascularisation or recruitment of existing capillaries secondary to an increase in haematocrit.

This is generally a scientifically sound paper and a well written manuscript. I have several comments for the authors:

\section{Major Comments}

It strikes me that the authors are trying to achieve two things in this paper. Firstly, to confirm that there is microcirculatory adaptation to altitude and hypoxaemia and to provide more information regarding the mechanisms surrounding this and secondly to describe a method of rapidly assessing vessel density. Both subjects are not quite covered in enough detail to do either justice.

With regard to the assessment method, this has been described previously in both buccal mucosa but also in other areas such as the nail bed. It has the advantage of being quick to perform but only provides information on one variable - number of capillary loops. The authors state and assume that this measure equates to Total Vessel Density (TVD) but it would be very useful to confirm this by actually measuring capillary TVD using sublingual IDF video capture and analysis. More importantly, the described method provides no measure of microcirculatory flow. This is crucial when discussing the impact of capillary haematocrit and viscosity on microcirculatory performance. Personally I think the paper would have been improved had the investigators used sublingual images and analyzed these to produce data on a fuller range of flow and density parameters.

Although the authors give two possible mechanisms for the observed increase in capillary density, I would be interested to know if these changes could possibly be accounted for by an increase in systemic haemodynamic parameters, such as cardiac output. Unless there is a loss of haemodynamic coherence one would expect that micro would follow macro. Measurement of these values using a non invasive technique such as trans thoracic echocardiography would have been interesting and added value to the paper. 
The authors discuss that systemic haematocrit and haemoglobin do not necessarily equate with capillary haemoglobin. This is a crucial point and one often observes that "shocked" capillaries have a visibly lower number of erythrocytes even in the presence of a reasonably preserved systemic $\mathrm{Hb}$ level, especially post resuscitation. Being able to quantify this difference would allow us to answer crucial questions but is not possible with current analysis methods using this technology.

I would be very interested to know how long this microcirculatory adaptation lasts. Did the authors consider repeating the measures after return to sea level and after a more prolonged period - e.g. one month?

\section{Minor Comments}

Southampton is spelt incorrectly in several places within the list of authors

Citing a validation paper of the IDF camera (e.g. Hutchings S, Watts S, Kirkman E. The Cytocam video microscope. A new method for visualising the microcirculation using Incident Dark Field technology. Clin Hemorheol Microcirc. IOS Press; 2015 Oct 16;62(3):261-71) would be useful as the authors have stated that it is a new device.

Competing Interests: No competing interests were disclosed.

I confirm that I have read this submission and believe that I have an appropriate level of expertise to confirm that it is of an acceptable scientific standard.

\section{Comments on this article}

\section{Version 1}

Reader Comment 07 Oct 2016

Dan Milstein, Department of Oral \& Maxillofacial Surgery, Academic Medical Center, University of Amsterdam, Amsterdam, The Netherlands

Some important elements regarding design and textual accuracy were completely missed by the authors and the reviewers.

The authors state that the CytoCam operates by emitting polarized light, this is incorrect.

Assessment of capillary density has been validated before and there are numerous reports available in humans and animals that show the applications of capillary density measurements (e.g. by Lindeboom et al. 2005 and onwards). The type of data presented in the manuscript may be infrequently used for investigating the topics of the current report on hypobaric hypoxia, but not in other fields and was drawn entirely from oral medicine and dentistry. The authors unfortunately did not refer to the source publications correctly referencing reproducibility and validation of capillary density measurements. The two citations that were used do not report validations of 
the analysis methodology. Why was intra-class correlation data not presented in the Results section of the report?

The microcirculation data was not divided by 1.79 to present a standardized unit of capillaries per $\mathrm{mm}^{2}$, which is identified in several papers as cpll//mm² for capillary density (CD) or functional capillary density (FCD), a completely different unit of analysis. As the data stands, it is not clear what the units are and it appears that the density data was interpreted as a number per $1.79 \mathrm{~mm}^{2}$ and not per $\mathrm{mm}^{2}$. Others might argue, but the only reason that dividing by 1.79 for capillary density counts is permissible for labial mucosa capillary density is because of counting of repeating (identical) vascular loops, a population count essentially, dividing by 1.79 would not work for branching vascular networks as in TVD or PVD.

Standardizing the data serves also another interesting role because the data from the CytoCam can then also be used to compare all previously obtained data with SDF imaging that also presents data on capillary density per $\mathrm{mm}^{2}$ in the visual field, this yields progress of the science and not always starting anew. Was normalization of the data thought of? One cannot assume that everybody has the same number of capillaries in their lips, some have more and others have less, that is why standardizing the data would allow clustered analysis and ease in trend assessments, especially when a repeated measurement in executed to trace the effects of a condition, in this case hypobaric hypoxia from ascending or return to normobaric normoxia from descent back to sea level.

The observations do not describe the consensus reports regarding TVD nor PVD, as detailed in the manuscript. TVD is reserved for network type (e.g. sublingual) analysis. This is why there should be different nomenclature for different anatomic compartments. Was there angioarchitecture classification performed, as presented by Weber et al. 2015? This classification provides a way of sorting the angioarchitecture and matching it with analysis methodology. For example, an array of capillary loops is a Class 1 angioarchitecture and fits with a field of view counting type analysis, a Class 2 is a hybrid between capillary loops and network vasculature and fits either a counting or AVA type analysis depending on the research question, and finally a Class 3 is exclusively network microcirculation fitting AVA and CCTools type analysis with TVD as $\mathrm{mm} / \mathrm{mm}^{2}$. The data should be in total capillary density (TCD) or actually functional capillary density (FCD). The data of capillary density is not the same as TVD. Depending on the scientific or clinical questions the investigators are trying to answer, the design of the study should take into consideration whether the study objectives are to investigate mucosal state implicitly or translate measurements of the reticular layer of the oral mucosa as a model representing central or systemic microhemodynamics.

In the first line of the Discussion, the first line in the Conclusions and in two more instances in between the Discussion and Conclusions, the authors refer to measurements of sublingual microcirculation obtained in their report. The report describes lip (labial) mucosa microvascular density measurements and not sublingual microvascular measurements.

There are more publications that report on validation of the CytoCam instrument before the report by Hutchings $S$ et al. 2015. Other topics that were mentioned such as neovascularization was not properly addressed. 
Finally, to understand the oral measurements, some knowledge of oral physiology is recommended. For example, since the oral mucosa of both the upper and lower lips are peppered with minor salivary ducts, their salivary secretions and associated microcirculation are controlled by shifts in sympathetic and parasympathetic mechanisms that may not lineup with identifying changes in capillary density in for example dry mouth from breathing, cold temperatures, high altitude hypoxia and compensatory autonomic activity in response to low atmospheric pressures and/or hypoxia.

Addressing these points would strengthen the scientific integrity of this report and improve research design for future studies.

Competing Interests: No competing interests were disclosed.

The benefits of publishing with F1000Research:

- Your article is published within days, with no editorial bias

- You can publish traditional articles, null/negative results, case reports, data notes and more

- The peer review process is transparent and collaborative

- Your article is indexed in PubMed after passing peer review

- Dedicated customer support at every stage

For pre-submission enquiries, contact research@f1000.com 